is made by pouring a 10 per cent solution of gelatine in water into a chamber formed between a flat glass plate and a mould that has been optically worked to the required contour. On cooling, the gelatine solidifies and sticks to the glass plate, and the mould can be removed. The gelatine gel is then left to dry out, when it shrinks to one-tenth of its thickness, but retains exactly the contour given to it by the mould; any unavoidable defects in the mould, such as minute surface scratches, being reduced in proportion.

The whole projection television unit is made possible by the efficiency and cheapness of the corrector plate, combined with the use of a small cathode ray tube. The receiver is likely to prove suitable for providing entertainment and instruction in, for example, schools and clubs. In addition, it may be used like other television receivers on a closed circuit for relaying purposes inside a building, such as for displaying a surgical operation to students outside and away from the operating theatre.

$$
1016
$$

\section{ORGAN PIPE TONES}

A LTHOUGH or tom flue pipes are in common use and thenpactical organ builder can from long experience p oduce, purely empirically, a variety of musical anes, the tone-producing mechanism is at presen nobscure. So far, investigations have been mare on the tones of pipes only in their finished dondition, without examining effects of the adjustments made in 'voicing' the pipe; thus two articles which have recently become available, describing measurements of the steady-state acoustic spectra of pipes undergoing voicing operations, represent a more thorough attack on the problem and are very valuable.

The first is by K. T. Kuhn* and is entitled "Klangfarbe und Wirbelform einer Lippenpfeife in Abhängigkeit von der Bauweise". Three square wooden pipes were used, each speaking the same note, but with different cross-sectional areas; each pipe was of special construction, with lips and languid movable. By altering the position of one of these parts at a time, different voicing adjustments could be simulated, and in each case a set of graphs is given showing the effect on the first six harmonics of the particular adjustment for each of the three crosssections. The effects are complex, since continued adjustment does not cause the harmonics to vary in a regular manner. It is surprising that no matter what is done to the pipe, the intensity of the fundamental varies comparatively little. The airflow at the mouth was also examined, stroboscopically, by the Schlieren method; qualitative agreement is shown between the mode of vibration of the airstream and the harmonic content of the tone.

In the second article, by $F$. Ingerslev and $W$. Frobeniust, which is in English and is entitled "Some Measurements of the End-corrections and Acoustic Spectra of Cylindrical Open Flue Organ Pipes", the dependence of the physical length of the pipe on the mouth dimensions is derived theoretically; good agreement is shown with several observed values. For the voicing tests seventeen pipes were used, all speaking the same note but differing in diameter and mouth dimensions, and the acoustic spectra are com-

Doctorate dissertation, Berlin (1940) ; FIAT microfilm PBL 78620 , reel $P$ 121, frames $6315-6334$.

† Trans. Danish Acad. Tech. Sci., No. 1, 7 (1947). pared and discussed. (It should be realized that the typical Danish pipe is of lighter and less forceful tone than its English counterpart.) Certain inhar. monic fluctuating components were found, but were considerably reduced by 'nicking'. The semiempirical formulæ given by J. G. Töpfer about a century ago, relating the dimensions of a pipe to its tone, were found to give fair agreement when tested. Measurements showed that, contrary to widespread belief, the edge-tone at the mouth is usually considerably higher in frequency than the fundamental of the pipe.

It is doubtless due to the practical experience of one of the authors of this second article as an organ. builder, that it is emphasized that a pipe must be correctly voiced and speaking its note properly for measurements on it to be of value; in practice it is seldom possible to adjust one variable alone over a wide range, so that it is doubtful if these conditions applied in the first article. The general conclusions of both papers confirm the estimates which have been made qualitatively on normal organ pipes. It is, however, clear, as the Danish authors stress, that much further investigation is required before organ tone can be thoroughly understood; the subtleties of tone which characterize an artistic voicer's work still await scientific analysis. D. M. A. MERCER

\section{POPULATION OF BRITISH 26 UNIVERSITIES DURING 1947-48}

THE “Returns from Universities and University Colleges in regeipt of Treasury Grants. Academic Year $1947-191 \%$, recently issued by the University Grants Confnittee, would, in any event, have been exayne fith particular interest as the first annual retr rn ssud since that for the year 1938-39. Quite aphat. from the light the returns throw on the course of aniversity expansion, observations by the Com. naittee of Public Accounts in its third report for the session 1948-49 should increase the keenness with which the return is scrutinized. That Committee observes that the Universities Vote raises difficult issues, since rapidly increasing sums are involved, both for recurrent grants and for capital expenditure. The estimate for $1949-50$ amounts to $£ 17,564,500$, as compared with $£ 12,480,000$ for $1948-49$, apart' from grants for the maintenance of students at the universities, also involving several millions of pounds but borne on other votes. Expenditure by universities, colleges, etc., in Great Britain out of the grantsin-aid is not accounted for in detail to the Comptroller and Auditor General, and the Committee of Public Accounts would like to see introduced more effective means of securing adequate Parliamentary control over this large expenditure of public money. The Committee was, however, impressed by the arguments advanced by the Treasury in favour of continuing the present system of administration without any enabling legislation. While the Com. mittee does not wish to press for such legislation in the circumstances now prevailing, it suggests that the Treasury should consider whether, without impairing the independence of the universities, any further means could be adopted to inform Parliament more precisely how the grant-in aid proposed in the

* Returns from Universities and University Colleges in receipt of Treasury Grants. Academic Year 1947-1948. (Univergity Grants Committee.) Pp. 28. (London: H.M. Stationery Office, 1949.)
18. 6 d. net. 